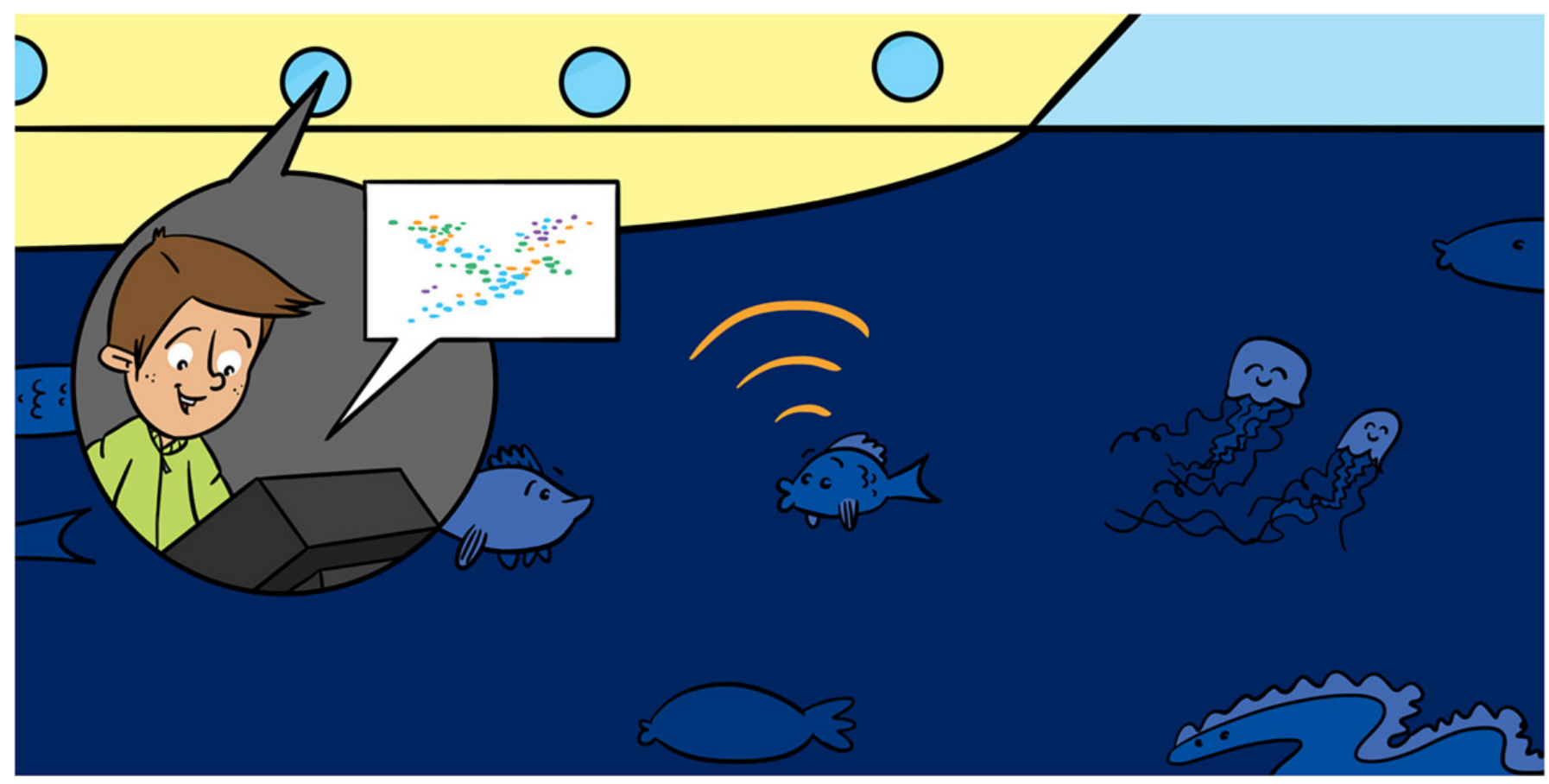

\title{
HOW DO SCIENTISTS USE SOUND TO COUNT FISH IN THE DEEP SEA?
}

\author{
Alina M. Wieczorek ${ }^{1 *}$, Amanda Schadeberg $^{2}$ and David G. Reid ${ }^{1}$ \\ ${ }^{1}$ Marine Institute, Galway, Ireland \\ ${ }^{2}$ Environmental Economics and Natural Resources Group, Wageningen University, Wageningen, Netherlands
}

\section{YOUNG REVIEWERS:}
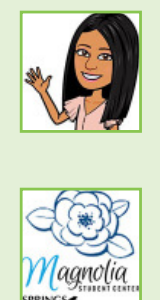

Magnolia

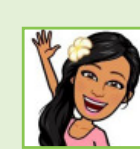

LEA

AGE: 11

MAGNOLIA STUDENT CENTER

AGES: 9-10

MILI

AGE: 8
Humans love to eat fish, but we must be careful not to catch too many. To make the right rules about how many fish can be caught without decreasing the population too much, it is helpful to know how many fish are in the sea. It is difficult for scientists to go underwater to count fish, but technology can help. Animals like dolphins can use sound to "see" the world around them. Just like dolphins, scientists can send a sound into the ocean and measure the echo that comes back. They can even use the unique echoes of fish to get an idea of how many fish are in the sea. Scientists are now testing whether this technology can help them to explore the deep sea. While it is not always easy to see with sound, the challenges we face and the mistakes we make often lead to new discoveries!

\section{ARE THERE PLENTY OF FISH IN THE SEA?}

Humans love to eat fish. We have become so good at catching them that we must be careful not to catch too many. We can protect the 
Figure 1

A transmitter (voice) sends out sound. The sound travels in waves that are reflected by an object, such as a wall. The reflected sound is called an echo or acoustic signal and can be picked up by the receiver (ears).

\section{SUSTAINABLE}

Able to be used in a way that makes a resource available for future generations.

\section{TRANSMITTER}

Something that sends out sound, like a voice or a loudspeaker.

\section{RECEIVER}

Something that receives or listens to sound, like your ears or a microphone.

\section{ACOUSTIC SIGNAL}

Sound that gets reflected back from an object.

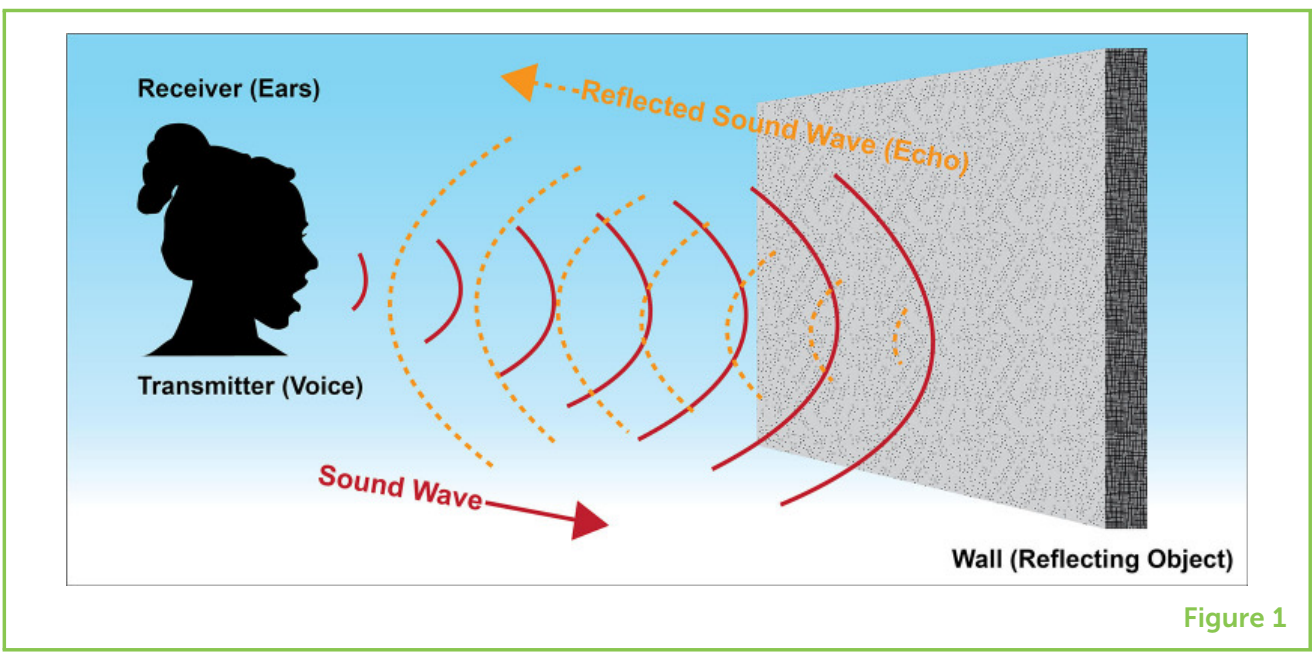

fish we like to eat by making rules about how many can be caught each year. If we leave enough fish behind, they will reproduce naturally so that there will be plenty to catch next time. If we have good rules to prevent overfishing, fish can be a valuable and sustainable food source [1].

To make the right rules about how many fish can be caught sustainably, it is important to know how many fish are in the sea. The ocean covers over $70 \%$ of the planet, so it is an enormous area to study. If you have ever looked at the ocean or a lake, you may have noticed that it is difficult to see far beneath the surface. For that reason, scientists have come up with methods to help them learn about the underwater world. For instance, they can catch fish with nets, they can scuba dive underwater, and they can ask fishers what they have caught. Sound is another tool scientists can use. But how can scientists use sound to "see" what is happening underwater?

\section{LOOKING WITH OUR EARS: USING SOUND TO SEE}

Sound travels in waves of energy. Like a wave of water, sound can get reflected by a surface and travel in another direction. Think of an echo in a big empty room. The sound travels in waves away from the transmitter, which can be your voice or a loudspeaker. Sound becomes an echo when it reflects off something and travels back to a receiver, which can be your ears or a microphone (Figure 1). The sound that gets reflected back will not be a perfect copy of what you transmitted. Scientists call this an acoustic signal. Depending on the shape of the object, the echo will scatter in different ways, producing a different acoustic signal.

Some animals have learned how to use sound to "see" the world around them. For example, dolphins transmit high-pitched sounds as they navigate their way around the sea. They then listen to the 
Figure 2

(A) Scientists on research boats send out sound from a transmitter (green beam) and measure the reflected echo or acoustic signal (orange lines). The sound scatters off the fish and other sea life in the water. (B) The echoes are processed into an image called an echogram, which shows the strength of the echoes by color. Interpreting echograms gives scientists clues about what is in the water below their boats.

\section{ECHOGRAM}

Literally a "sound drawing;" a picture made by processing acoustic signals into an image.

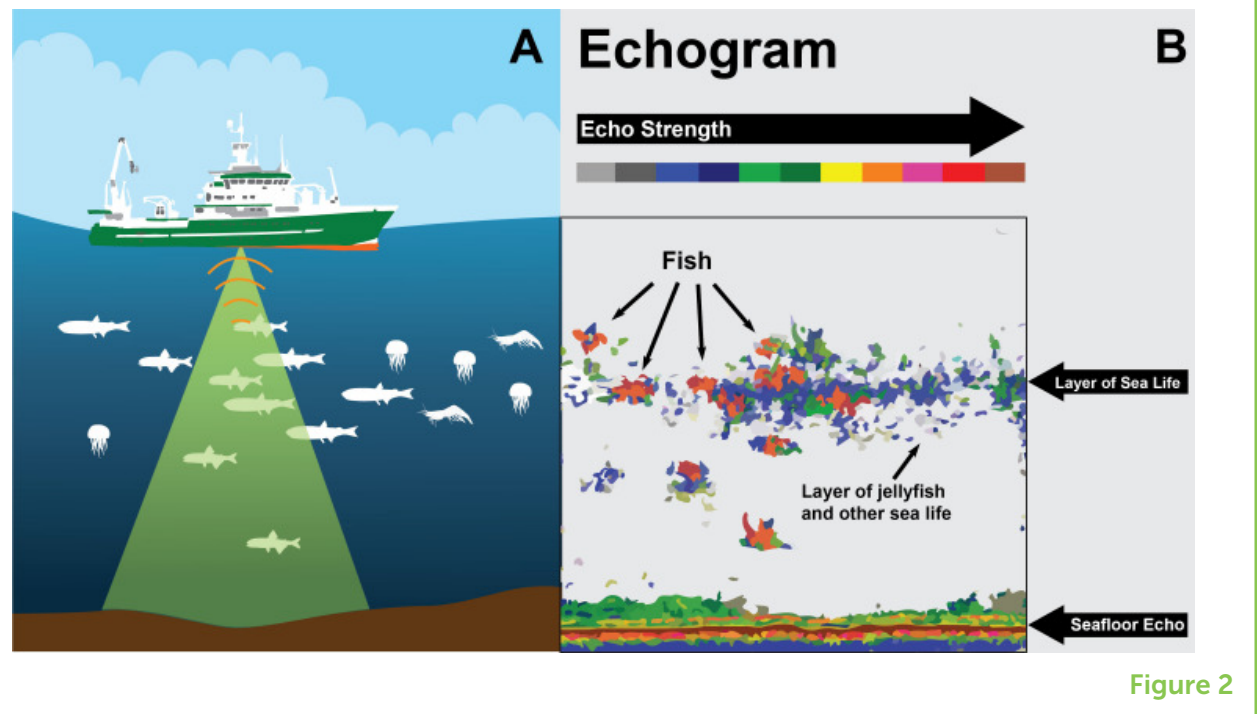

returning echoes and their brains process the echoes into an image of the world around them. This helps dolphins to catch fish and avoid obstacles, even in pitch darkness.

\section{"DISAPPEARING" SEA FLOORS: HOW A MISTAKE HELPED SCIENTISTS LEARN TO USE A NEW TECHNOLOGY}

Scientists have learned that, like dolphins, we can use sound to see objects underwater. Dolphins use their brains to process sound into a mental map. Our brains are not adapted to "seeing" with our ears, so we use technology to process sounds into images on paper or computers. We call these images echograms. The word "echogram" is a combination of the ancient Greek words for "sound" (echo) and "that is drawn" (-gram)-so, literally, an echogram is a "sound drawing." The shapes and colors on echograms reflect the strength and location of an acoustic signal. These echograms help us to "see" the sea floor, hundreds of meters below (Figure 2).

Interpreting echograms takes a lot of experience and sometimes scientists make mistakes. For example, echograms were used to make ocean maps to help prevent ships from running aground on the seafloor. Sometimes an echogram would show that a part of the sea was shallow enough to be dangerous for boats. These shallow areas were marked on a map so that other boats could avoid them. However, another captain returning to the same area would find that the water was much deeper than the map showed. Scientists later learned that some areas that were mapped as having shallow sea floors actually contained dense layers of sea life, made up of fish and jellyfish [2]. There was so much marine life in the water that the echo from all the animals together sounded the same as the echo from the sea floor! While scientists knew that they could use sound to locate fish 


\section{AIR BLADDER}

A small organ that fish and siphonophores can fill with air, to help them float and move up and down in the water.

\section{MESOPELAGIC}

\section{ZONE}

The part of the ocean that is $200-1,000$ $m$ deep. in the water [3], they did not expect to find so many animals so close together. Luckily, mistakes in science can lead to new discoveries. In this case, scientists learned that what they thought was the sea floor was actually dense clusters of marine animals!

\section{HOW IS A FISH LIKE A DRUM?}

Scientists are constantly improving the quality of their instruments and learning more about how to use acoustic technology to observe fish. While acoustic signals were first used to simply measure depth, modern echograms can return much more detailed information. Today, scientists can often tell what type of fish is in a school by interpreting the details of an echogram. Scientists can do this because of the unique biology of fish. Fish have many similar organs to humans such as eyes, a brain, stomach, liver, and kidneys. They also have some different ones that are adapted to their environment. Gills are one example, which help fish to breathe underwater. Another adaptation that they have is something called an air bladder (also called a swim bladder). This is a sack of air that helps fish control their depth in the water. If they fill up the air bladder, they will float closer to the surface, and if they release some of the gas, they will stay deeper underwater.

Air bladders reflect sound particularly well. Just like a drum, an air bladder is an empty space filled with air. When it is hit by a sound wave, the air bladder produces a strong echo. The strength of the echo depends on the size and shape of the air bladder. This is the same with drums: a small drum will produce a short, high-pitched sound, and a large drum will produce a long, low-pitched sound. As you know, different species of fish have different shapes and sizes. Luckily for scientists, the shapes and sizes of their air bladders are also different. This causes fish to produce unique echoes, which appear quite different on an echogram.

For this technique to work, scientists must match the acoustic signal in the echogram with a particular species of fish. They do this by catching a small number of the fish with nets and recording what the echogram looks like when sound is reflected off them. The next time they see a similar signal on the echogram, they will know which fish species are swimming below them in the water-without having to catch them in a net!

\section{GOING DEEPER: USING SOUND TO EXPLORE THE MESOPELAGIC ZONE}

Scientists are interested in a deep part of the ocean known as the mesopelagic zone. This is the part of the ocean that is $200-1,000 \mathrm{~m}$ deep. Very little sunlight can penetrate the water at this depth. Because 


\section{Figure 3}

Mesopelagic fish (bottom) and siphonophores (top) both have air-filled organs called air bladders. Air bladders help the fish and siphonophores to control their depth in the water, and they reflect sound very well.

\section{SIPHONOPHORE}

A soft underwater animal similar to a jellyfish.

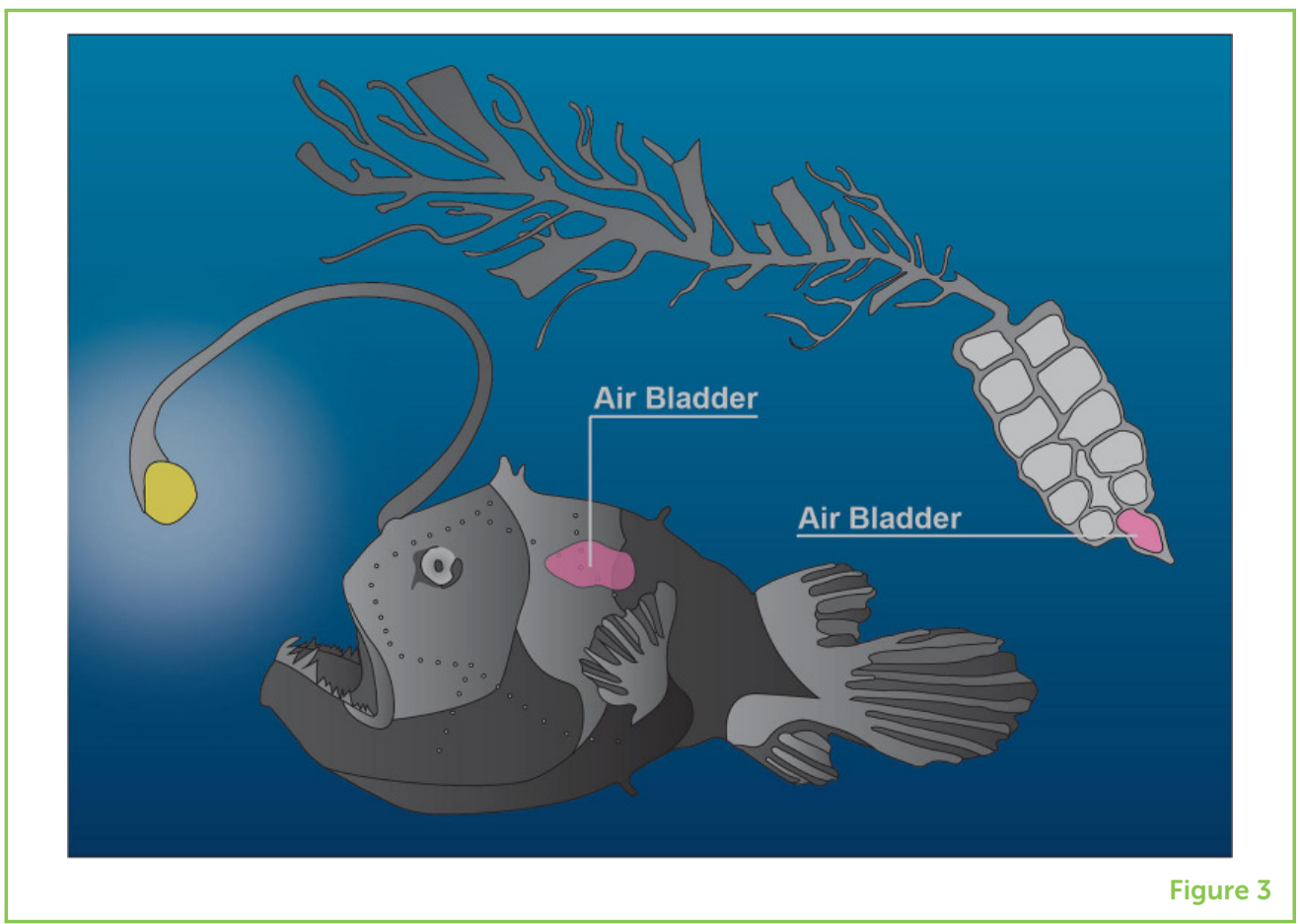

of the lack of light, it is sometimes referred to as the ocean's "twilight zone." Lots of fascinating creatures live there. However, because it is so difficult to reach, we do not know a lot about the mesopelagic zone of the ocean. To help imagine how deep the mesopelagic zone is, consider this: an Olympic swimming pool is $50 \mathrm{~m}$ long. To get to $1,000 \mathrm{~m}$ deep, you would have to swim 20 laps-straight down! This would take an average scientist around 45 minutes.

Luckily, sound travels much faster than a swimming scientist. Sound can get to $1,000 \mathrm{~m}$ and back in less than two seconds. Thanks to this, scientists can create lots of echograms telling them what is happening deep below their boats. This helps them to count how many fish live in the mesopelagic zone. Knowing how many fish are down there will be important in the future, if humans want to catch these fish.

As you have learned so far, it is not always easy to "see" using sound, especially not in the deep ocean. Trying to count fish here means overcoming many obstacles. For example, along with lots of fish, we can find siphonophores in the deep sea. Siphonophores are alien-looking animals similar to jellyfish. Like fish, they have air-filled organs that help them to move up and down in the water (Figure 3). Because of these organs, siphonophores produce echoes like those of fish [4]. To tell the difference between fish and siphonophores in echograms, scientists need to collect more detailed acoustic signals. To do so, they work with engineers to try to develop new acoustic instruments. 


\section{ACOUSTIC TECHNOLOGY HELPS US MAINTAIN A SUSTAINABLE OCEAN}

Acoustic technology uses sound to help scientists estimate how many fish are in the sea. This knowledge is important for governments and other decision-makers because it helps them to create rules about how many fish can be caught. Limiting the number of fish that can be caught has helped many fish species recover from overfishing in the past. Scientists are working to collect information about fish that live in the deep sea, so that we can avoid overfishing them in the first place. Seeing with sound, using acoustic technology, can help deep-sea fishing to be more sustainable from the very beginning!

\section{ACKNOWLEDGMENTS}

This article has emanated from research under the MEESO project (ecologically and economically sustainable mesopelagic fisheries), which has received funding from the European Union's Horizon 2020 research and innovation programme under grant agreement No 817669.

\section{REFERENCES}

1. Worm, B., Hilborn, R., Baum, J. K., Branch, T. A., Collie, J. S., Costello, C., et al. 2009. Rebuilding global fisheries. Science. 325:578-85. doi: 10.1126/science.1173146

2. Dietz, R. S. 1962. The sea's deep scattering layers. S Am. 207:44-51.

3. Sund, O. 1935. Echo sounding in fishery research. Nature. 135:953. doi: 10.1038/135953a0

4. Proud, R., Handegard, N. O., Kloser, R. J., Cox, M. J., and Brierley, A. S. 2019. From siphonophores to deep scattering layers: uncertainty ranges for the estimation of global mesopelagic fish biomass. ICES J Mar Sci. 76:718-33. doi: 10.1093/icesjms/fsy037

SUBMITTED: 24 August 2020; ACCEPTED: 25 November 2021; PUBLISHED ONLINE: 21 December 2021.

EDITED BY: Laura Lorenzoni, National Aeronautics and Space Administration (NASA), United States

CITATION: Wieczorek AM, Schadeberg A and Reid DG (2021) How do Scientists Use Sound to Count Fish in The Deep Sea? Front. Young Minds 9:598169. doi: 10. 3389/frym.2021.598169

CONFLICT OF INTEREST: The authors declare that the research was conducted in the absence of any commercial or financial relationships that could be construed as a potential conflict of interest. 

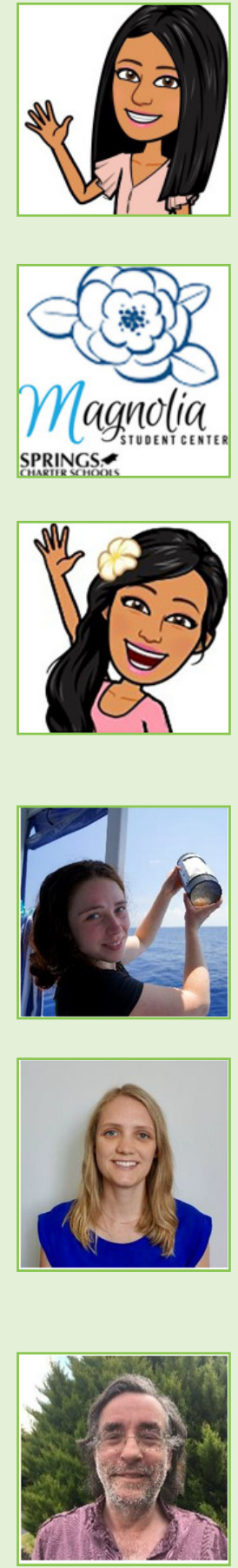

COPYRIGHT @ 2021 Wieczorek, Schadeberg and Reid. This is an open-access article distributed under the terms of the Creative Commons Attribution License (CC BY). The use, distribution or reproduction in other forums is permitted, provided the original author(s) and the copyright owner(s) are credited and that the original publication in this journal is cited, in accordance with accepted academic practice. No use, distribution or reproduction is permitted which does not comply with these terms.

\section{YOUNG REVIEWERS}

\section{LEA, AGE: 11}

$\mathrm{Hi}$, I am Lea and I am in 5th grade in a STEM school. I have an 8 years old sister. I enjoy dancing, acting, drawing, and reading books. My favorite genre of books is mystery. My favorite animal is a dog and I have 3 guinea pigs. When I grow up I want to be an actress or a ballerina.

\section{MAGNOLIA STUDENT CENTER, AGES: 9-10}

We are a 4th grade class in Riverside, California. We enjoy learning about science, and our goal is to be lifelong learners.

\section{MILI, AGE: 8}

My name is Mili and I am 8 years old. I like reading and maths. I enjoy playing the piano. When I am older, I want to become a teacher.

\section{AUTHORS}

\section{ALINA M. WIECZOREK}

I am a post-doctoral scientist researching mesopelagic fish acoustics and ecology. I am based in the Marine Institute on the beautiful, but rainy, west coast of Ireland. I also went to university here and completed my Ph.D., studies on microplastics in ocean systems. *Alina.Madita@googlemail.com

\section{AMANDA SCHADEBERG}

I am a Ph.D. candidate studying the governance of mesopelagic fishing. I work at Wageningen University in the Netherlands. I like to research topics related to society and marine resources. I have previously worked on understanding fisher behavior and have contributed to projects about marine plastic, environmental risk assessment, and stakeholder consultation.

\section{DAVID G. REID}

I have worked for 30 years in fisheries management, starting out in fisheries acoustics in Scotland, working with some of the top scientists in the field. I now work on fisheries sustainability, fishing capacity and effort, industry collaboration, Integrated Ecosystem Assessment, and Ecological Risk Analysis. I am the Principle Investigator on Ecosystem Based Fisheries Management at the Irish Marine Institute and am adjunct professor at University College Cork, Ireland. 